\title{
A Comparative View of Glacial and Periglacial Landforms on Earth and Mars
}

\author{
Anna Grau Galofre (Arizona State University) \\ Contact: agraugal@asu.edu; +1 4806523893
}

\section{With}

Chimira N.Andres (University of Western Ontario)

Patricio Becerra (Universität Bern) Anshuman Bhardwaj (University of Aberdeen) Ali Bramson (Purdue University) Frances Butcher (University of Sheffield) Philip R. Christensen (Arizona State University) Susan J. Conway (CNRS/ Université Nantes) Andrea Coronato (CADIC-CONICET; Universidad Nacional de Tierra del Fuego)

Ernst Hauber (German Aerospace Center/ Institute of Planetary Research) Shannon Hibbard (University of Western Ontario)
J. Paul Knightly (University of Arkansas) Tyler Meng (University of Arizona) Gordon R. Osinski (University of Western Ontario)

Eric I. Petersen (University of Arizona)

Jeff Plaut (NASA Jet Propulsion Lab) Jorge Rabassa (CADIC-CONICET, Academia

Nacional de Ciencias de Argentina, IEC) Alicia M. Rutledge (Northern Arizona University) Lydia Sam (University of Aberdeen) Jayanth Serla (Arizona State University) Kelin X. Whipple (Arizona State University)

\section{Co-signatories}

Munkhnast Amar (National University of Mongolia)

Dale T. Andersen (SETI Institute)

Jonathan Bapst (NASA Jet Propulsion Lab)

Jim Bell (Arizona State University)

Shane Byrne (University of Arizona)

Matthew Chojnacki (Planetary Science Institute)

Jonathan Clarke (Australian Center for Astrobiology)

Serina Diniega (NASA Jet Propulsion Lab)

Cynthia L. Dinwiddie (Southwest Research Institute)

Amber L. Gullikson (USGS Astrogeology Science Center)

Jack W. Holt (University of Arizona)

Briony Horgan (Purdue University)

Devanshu Jha (MVJ College of Engineering, India)

Andreas Johnsson (University of Gothenburg)
Corbin Kling (North Carolina State University) Alexandre Mangeot (Hybrid Propulsion for Space) Michael Mischna (NASA Jet Propulsion Laboratory)

Stefano Nerozzi (University of Arizona) Rachel W. Obbard (SETI Institute)

Marisa Palucis (Dartmouth College)

Ashley Palumbo (Brown University)

Elizabeth Rampe (NASA Johnson Space Center) Isaac Smith (York University and Planetary Science Institute)

Anushree Srivastava (The Open University, UK) Anastasia Stepanova (Institute of Biomedical Problems)

Timothy Titus (U.S. Geological Survey Astrogeology Science Center) Jacob Widmer (N/A, University of Maryland)

\section{A White Paper Submitted to the NRC Planetary Science Decadal Survey July 14,2020}

This white paper supports the commitment to excellence in planetary science research through advancement of equity, diversity, and inclusion. 


\section{The case for studying the glacial record of Mars}

The (peri)glacial landforms of Mars record the history of water-surface interactions of the last 3.5 Byr. The geological record of Mars is unique among other planetary bodies in the solar system, aside from Earth, given the long-term interaction between water and the surface. This makes Mars more similar to Earth than any other planetary body and has potentially profound implications for the origin and evolution of extraterrestrial life. Whereas early Mars, 33.9-3.5 Byr ago, experienced surface liquid water activity ${ }^{1,2}$, Mars has remained a frozen planet for most of its history.

The Martian water inventory is largely stored in the form of ice in the polar caps and midto high- latitudes. Approximately 5 million cubic kilometers of water ice lie currently at or near the Martian surface ${ }^{3}$. The polar caps are the largest reservoir, containing $\sim 22 \mathrm{~m}$ Global Equivalent water Layer (GEL), followed by at least $7 \mathrm{~m}$ GEL contained in ground ice, and $\sim 2.6 \mathrm{~m}$ in midlatitude shallow buried ice, sequestered in Latitude-Dependent Mantle (LDM), Lobate Debris Aprons (LDA), Lineated Valley Fill (LVF), Concentric Crater Fill (CCF), and Glacier Like Forms $(\mathrm{GLF})^{3-5}$.

The identification of ice deposits relies heavily on orbital characterization of their surface morphologies. Glacial landforms on Mars are produced by the accumulation, motion, and deformation of crystalline water ice. They involve relatively recent and on-going accumulations in the polar caps, preserved ice deposits in Viscous Flow Features (VFFs) such as LDAs, GLFs, CCF, LVF, and relict landforms with no presence of remnant ice. VFF morphology includes convex surface profiles, surface sublimation textures, deflation, and lineation patterns related to deformation $^{6}$, and high subsurface radar reflectivity ${ }^{7}$. Examples of relict landforms include glacial valleys $^{8,9}$, subglacial channels ${ }^{10}$, moraine-like arcuate ridges and drop moraines ${ }^{11,12}$, eskers ${ }^{13,14}$, etc. Landforms interpreted to be periglacial in origin are widespread across the mid to high latitudes and are associated spatially with other evidence for ground ice. However, this interpretation is not unanimous. Processes that shape periglacial landforms include cycles of volumetric thermal contraction and expansion of permafrost, including condensation-sublimation and possibly freeze-thaw. Patterned ground, such as polygonal terrain and brain terrain ${ }^{15}$, are often cited as evidence of periglacial processes on Mars.

The type, morphology, distribution, and ice content of (peri)glacial landforms reflect the past local and global climate conditions. Climate is a key control on the mass-balance, flow, and surface expression of ice in several ways ${ }^{16}$. For example, the accumulation of snow and its transition to crystalline ice requires thousands of years of climate stability during ice accretion and preservation $^{17}$. Temperature, dust content, and ice thickness, all play a major role in shaping the deformation textures of ice ${ }^{16}$. Moraines and trimlines map the previous extent and thickness of ice bodies, providing evidence for thicker, more extensive deposits in the past, as well as witnessing episodes of glacial advance and retreat. The presence of specific glacial landforms such as striations, subglacial channels, and eskers, as well as the detection of hydrated silica in (peri)glacial terrains indicate that basal water accumulation occurred ${ }^{18,19}$, with implications for climate and habitability. Similarly, the distribution, mineralogy, and morphology of periglacial landforms reflect past climate conditions including ground-surface temperature oscillations, precipitation, lag deposit accumulation rate, and water content, but their formation mechanisms are still poorly understood. 
The identification of sites with subsurface ice, with potential for in-situ resource utilization of future human missions and of astrobiological interest, relies on the correct interpretation of the glacial/periglacial record. In preparation for future human exploration, the identification of sites with in-situ resources based on key distinctive landforms is important, in particular, to characterize the presence of readily accessible water ice. Although the Shallow Radar (SHARAD) is able to provide evidence for the presence of ice and its thickness, its horizontal resolution (0.3$3 \mathrm{~km}$ ) prevents a detailed characterization of a specific landing site. Therefore, it is key to characterize Martian (peri)glacial morphologies with high-resolution imagery and topographic data, and quantitatively relate them to physical aspects such as ice content, depth, distribution and spatial extent. Advancing our knowledge regarding the identification, characterization, and interpretation of ice-related landforms on Mars will help inform the selection of landing sites for future missions targeting the search of life and the human exploration on $\mathrm{Mars}^{20}$.

\section{Progress to this point}

The identification of (peri)glacial features on Mars started with the early Viking image data ${ }^{13,21}$. Since then, understanding has progressed remarkably thanks to many orbital missions, as well as the Phoenix lander, enabling an increasingly better understanding of the spatial and temporal characteristics of the Martian cryosphere.

Glacial features: progress. The identification of ancient, relict glacial landforms (other than the polar caps) started from early morphological interpretations of glaciofluvial and alpine glacial erosion features $^{13}$. Similarly, geomorphic studies first hypothesized that VFFs were extant ice deposits covered in debris ${ }^{21}$, later confirmed by SHARAD observations ${ }^{22,23}$. Geomorphology also aided the characterization of tropical glacial fingerprints ${ }^{11}$, and the identification of recurrent glaciation in the mid- to low- latitudes, providing evidence that obliquity controls the cyclical accumulation of a latitude dependent mantle (LDM) ${ }^{12}$. Recently, scarps exposing buried extant ice sheets in the mid-latitudes have been identified, providing evidence of a much more substantial glaciation ${ }^{24}$. Other significant advances include the identification of ancient eskers in the southern circumpolar region ${ }^{25,26}$; the confirmation that the polar caps of Mars contain water ice and are not flowing substantially ${ }^{28}$; the identification of geologically-young eskers in the mid-latitudes ${ }^{14,29}$; and the possible presence of a subglacial lake under the southern polar cap ${ }^{30}$. Geomorphology has aided in the identification of relict and extant glacial landforms, from the poles to the equator, and corresponding to various ages.

Periglacial landforms: progress. Similarly, geomorphological interpretations of periglacial landforms first aided in the identification of ground ice on Mars, with later efforts focusing on the link between distribution and morphology of patterned ground and buried ice ${ }^{31-33}$. High resolution imagery, gamma ray spectrometry, and thermal inertia data enabled the first quantitative evidence of the presence of near-surface ground ice ${ }^{32,33}$, followed by the in-situ detection of a shallow ice table $\left(5-18 \mathrm{~cm}\right.$ depth) below polygonal terrain by the Phoenix mission ${ }^{36}$. Ongoing efforts by the SHARAD and MARSIS radar experiments are key to interrogate the distribution and depth of subsurface ice deposits ${ }^{37}$. In combination with geomorphological mapping, significant ice deposits have recently been identified in Arcadia and Utopia Planitia ${ }^{40,37,41}$. The identification of ground ice is currently the focus of the Subsurface Water Ice Mapping on Mars (SWIM) team ${ }^{38,39}$, and is a main goal of a future Mars Ice Mapper mission. Additionally, an increasing body of evidence from morphological and mineralogical ${ }^{18}$ studies of potentially relict periglacial landform 
morphology suggests that liquid water (wet periglaciation) occurred in recent periods of high obliquity $^{42,43}$.

\section{The case for (peri)glacial comparative geomorphology}

Earth provides a natural laboratory with surface processes comparable to those on Mars, which we can access and understand, and then extrapolate to infer characteristics of the Martian climate, geology, and water budget. No analogue site on Earth is perfect, however, as conditions such as $\mathrm{CO}_{2}$ condensation or sublimation-dominated mass balance can only be captured in laboratories and numerical models. By studying ice-related features through planetary and terrestrial analogues, high-impact goals can be achieved, such as:

- Characterizing the morphology and characteristics of ice-related landforms in situ, to relate morphology, ice content, distribution, and driving processes using, e.g., geophysical techniques (e.g., ground penetrating radar (GPR) and geoelectrical surveys), ice cores, and modelling. (MEPAG goals II and III).

- Advancing the techniques required for the characterization of ice-related landscapes, which will be necessary in future Mars missions to assess the presence, content, depth, and distribution of ice. (MEPAG goal IV).

- Understanding the environmental settings where specific landforms developed in terms of climate, lithology, topography, and solar insolation. (MEPAG goal II).

- Describing and cataloguing (peri)glacial processes, (peri)glacial alteration products, and landforms on Earth itself, which will soon degrade and/or thaw under a warming climate.

- Characterizing the dynamics and landforms attributed to the presence and motion of ice on Earth and Mars, which can then be used to help understand the landscape and evolution of the surfaces of icy bodies and ocean worlds, including Europa, Enceladus, and even Pluto.

\section{Suggested sites of interest for analogue research}

Below is a list of sites of special interest for their comparison to Martian environments, including a justification in terms of environment, process, preservation, landforms, and astrobiological interest (if applicable).

\section{Polar regions}

Analogue sites in polar areas (above the Arctic circle and below $60^{\circ} \mathrm{S}$ ) offer the most analogous terrains for Mars' (peri)glacial landscapes. Environments are characterized by extremely cold temperatures, and either heavy glaciation or hyperarid, polar desert conditions.

\section{Canadian Arctic Archipelago}

The subdued topography of the sedimentary basins in the high Canadian Arctic provides a unique space for (peri)glacial analogue research.

- Devon Island: Considered an excellent analogue to Mars ${ }^{44}$, Devon Island features an Arctic ice cap ${ }^{43}$, subdued topography, and a polar desert climate ${ }^{44,46}$. The island contains extensive (peri)glacial landforms, some of them unique, such as relict subglacial channel networks ${ }^{47}$, extensive examples of patterned ground, and analogues to brain terrain ${ }^{48}$. A hypersaline 
subglacial lake exists under the Devon ice cap, in a region previously deemed too cold for liquid water ${ }^{49}$. The Haughton-Mars Project (HMP) and the F-MARS project compile 20 years of analogue investigations, including the characterization of the Haughton impact structure and studies of the morphology of meltwater valleys $\mathrm{s}^{44,45}$.

- Axel Heiberg Island: Axel Heiberg Island is characterized by polythermal ice caps, higher relief variability than Devon, and sandstone dominated substrates. Axel Heiberg's subglacial channels are potential analogues to some valley networks ${ }^{51}$, cold and polythermal glaciers yield a wide range of glacial landforms, and there is a variety of patterned ground. The presence of the Sverdrup Basin flood basalts, as well as extensive salt-ice interactions, make Axel Heiberg a mineralogical analogue for glacial chemical alteration and astrobiology ${ }^{52}$.

\section{Antarctica}

McMurdo Dry Valleys namely Beacon and Mullins valleys: The frigid and extremely hyperarid conditions mean that ice sublimation dominates over melt. The region contains examples of sublimation-driven patterned ground overlying debris-covered glaciers ${ }^{5}$, extensive patterned ground, and massive ground ice. The debris-covered, cold-based glaciers in Mullins valley contain ancient ice $\left(\sim 8 \mathrm{Myr}^{53}\right)$ and are good analogues to tropical glaciers in the Arsia Mons region of Mars ${ }^{11}$. Seasonal episodes of ephemeral melt are a promising analogue to capture a 'cold and icy' early Mars hydrological system, addressing valley network formation from snowmelt ${ }^{54}$. The Asgard range region also preserves relict networks of subglacial channels ${ }^{55}$, possible analogues to some Martian valley networks ${ }^{51}$. Exposures of the mafic Ferrar dolerite unit, and presence of brines (e.g., Don Juan Pond) pose additional interesting mineralogical and astrobiological analogues.

\section{Scandinavian Arctic}

- Svalbard, Norway: The Svalbard archipelago features moderately warmer and wetter polar climate than other polar regions, allowing for higher presence of melt and the development of wetter periglacial landforms.

- Spitsbergen Island exhibits a wide range of (peri)glacial landforms in close spatial proximity, including active stone circles, ice-wedge polygons, and pingos ${ }^{56}$, as well as glacial landforms such as eskers, moraines, and meltwater channels. The island has well-preserved patterned ground analogues to western Utopia Planitia, Mars ${ }^{57}$.

- The Arctic Mars Analog Svalbard Expedition was established to combine the investigation of analogue Arctic astrobiology environments with active testing of scientific instruments. Payload testing included the CheMin, SAM, PanCam (MSR), and the WISDOM and FTIR experiments (Rosalin Franklin rover).

- Swedish Arctic: The Swedish Arctic features multiple (peri)glacial landforms of interest, including thermal contraction polygons, solifluction lobes or thaw slumps, as well as wellpreserved relict erosional remnants of glacial valleys, eskers, and moraines ${ }^{58-60}$.

\section{Subarctic and lowland permafrost regions}

\section{Iceland}

Iceland provides a unique analogue setting to study the interactions between a variety of volcanic, glacial, and periglacial processes including: 
- Lava-ice interactions, including records of large subglacial floods (jökulhlaups) triggered by volcanic eruptions beneath the Vatnajökull ice cap and surrounding glaciers.

- Adjacent active and relict rock glaciers in the Tröllaskagi peninsula, allowing for accurate direct comparative studies including change monitoring and landform dating.

- Well-preserved relict patterned ground and polygonal terrain in the Westfjords and Highlands, dating to Last Glacial Maximum and Little Ice Age, enable comparative studies with active patterned ground sites elsewhere to derive rates of morphologic change ${ }^{61}$.

- Eskers in the Breiðamerkurjökull area have similar cross-section to those in Phlegra Montes ${ }^{14}$.

\section{Northwestern territories, including the Tuktoyaktuk Peninsula}

Tuktoyaktuk peninsula marked the northern boundary of the Laurentide ice sheet. Its subdued topography is marked by thousands of pingos, including some of the world's largest. The region exhibits massive ground ice, ice wedge polygons, tundra lakes, kettle-lake topography, tunnel valleys, subglacial and proglacial channels ${ }^{62}$, and has been considered a good analogue for possible 'wet' periglacial landforms in Utopia Planitia ${ }^{63}$.

\section{Siberia}

Dominantly of subarctic climate, Siberia is arguably one of the best terrestrial analogue sites for the study of Martian ground ice ${ }^{64}$. Permafrost in southern Siberia dates back to $3 \mathrm{Myr}$, among the oldest continuously frozen regions on Earth ${ }^{65}$. Northern Central Siberia displays some of the thickest ground ice deposits in the world (1-1.5 $\left.\mathrm{km}^{64}\right)$. In addition, thermokarst in ice-rich Siberian permafrost has been compared to scalloped depressions on Mars ${ }^{66}$. Examples of subice volcanism analogues are also apparent in Tuyas in the Azas Plateau ${ }^{67}$.

\section{High mountain environments}

The high relief and presence of active or relict (peri)glaciation, combined with a better accessibility, make alpine and plateau environments a desirable analogue to Martian icy terrains.

\section{Alaska}

Presence of active (peri)glaciation and ice-volcanic interactions such as:

- Hydromagmatic eruptions through thick permafrost layers in the Seward Peninsula, producing kilometer-scale Maars style craters ${ }^{68}$, and lava-ground ice interactions ${ }^{69}$.

- Glacial and periglacial sedimentology variability record obliquity-driven climate change ${ }^{68}$.

- More than 200 debris-covered glaciers (DCG), such as the Sourdough glacier located in the St. Elias range, used as a Mars analogue ${ }^{70}$.

\section{Western US}

Plateaus in the Uinta Mountains of north central Utah support well-preserved relict patterned ground dating to the LGM and LIA ${ }^{61,71}$. Active rock glaciers are found here and extensively in the Sierra Nevada, CA.

\section{Western Himalaya}


Permafrost features on steep slopes in the cold and arid regions in Ladakh and Karakoram Himalaya $^{72,73}$ display unique flow patterns and morphologies. Rock glaciers and ice-debris complexes are similarly influenced by the high relief, with distinct deformation patterns.

\section{Patagonia and Tierra del Fuego (Argentina/ Chile)}

The Patagonia region supports a variety of glacial, glaciovolcanic, and periglacial features of interest. In spite of its unique geomorphology, the region still lacks analogue recognition. This region features:

- Geological record of multiple cycles of advance and retreat of glaciers, featuring glacial, glaciofluvial and volcanic landforms that originated as early as $7 \mathrm{Myr}$ ago $^{74-77}$.

- Large glacial lakes, such as the Argentino and Viedma lakes, including active morainedammed lakes that yield current-day large outburst floods ${ }^{78,79}$.

- Steep topography may capture the dynamics of (peri)glaciation in crater walls ${ }^{51}$.

- Debris-covered glaciers, such as the Mt. San Lorenzo (S. Patagonia), with debris deposition triggered by tectonic/ mass wasting processes or by intense precipitation.

- Lateral moraines, drumlins, ribbed moraines, and glaciofluvial landforms appear along the Gallegos river valley, several older than $1 \mathrm{Myr}$ and emplaced without basal meltwater ${ }^{80,81}$. Ribbed moraines indicate cold- to wet-based transitions in glacial ice, of interest for Mars.

\section{Other}

High mountain environments of analogue interest are also identified in the European Alps, Carpathians, the Rocky Mountains, etc. Kibo summit of Mt. Kilimanjaro, for example, features a hyperarid sublimation environment with cold-based glaciers, of mineralogical interest. Analogue terrains in these areas are generally better characterized and more accessible than other sites.

\section{In-situ characterization of icy terrains: the next natural step}

Quantifying the distribution and volume content of near surface ice is of primary importance to allow for In-Situ Resource Utilization (ISRU) for human exploration (MEPAG goal IV). Future missions such as the Mars Ice Mapper, as well as recently proposed missions, such as $\mathrm{COMPASS}^{81}$, would allow for a detailed characterization of ground ice-atmosphere interactions. Going forward, the next necessary and natural step is the in-situ characterization of ice resources ${ }^{83}$, 84 .

The techniques in Table 1 are used extensively for the characterization of (peri)glacial terrains on Earth. The first three techniques target the characterization of terrain geomorphology, surface chemistry, and hydrogen content. The remaining techniques are aimed at interrogating the subsurface ice: distribution, volume, stratigraphy, and dust content, the ice-atmosphere exchange, and characterizing the surface processes. Ground ice coring and field reconnaissance of analogue sites provide observational constraints on the remote investigation ${ }^{84,85}$. A mission combining all these elements, which could be achieved through a combination of an uncrewed aerial vehicle (UAV) and a lander or rover, would provide a detailed characterization of the ice content, distribution, and depth of an ice deposit on Mars. This has significant implications not only for the localization of ice-rich sites and geological characterization of these, but also for ISRU and management of water as a resource on the Martian mid-latitudes for future exploration missions. 


\begin{tabular}{|c|c|c|}
\hline Techniques & Platform & Target(s) \\
\hline $\begin{array}{l}\text { Imaging: optical, thermal, } \\
\text { hyperspectral }\end{array}$ & Orbiter & $\begin{array}{l}\text { - Water content } \\
\text { - Alteration mineralogy }\end{array}$ \\
\hline Imaging: thermal and optical & \multirow{2}{*}{ UAV } & \multirow{2}{*}{$\begin{array}{l}\text { - Fine-scale morphology, grain size characterization } \\
\text { - Landforms \& landform evolution } \\
\text { - high resolution topography }\end{array}$} \\
\hline Stereo-derived/LiDAR DTM & & \\
\hline Ground penetrating radar (GPR) & \multirow{4}{*}{$\begin{array}{l}\text { Lander or } \\
\text { rover }\end{array}$} & \multirow{4}{*}{$\begin{array}{l}\text { - Subsurface ice content, distribution, depth, volume } \\
\text { - Ice and dust stratigraphy } \\
\text { - In-situ reconstruction of ice cores, climate record } \\
\text { - Mass-balance and atmospheric exchange }\end{array}$} \\
\hline $\begin{array}{c}\text { Micro Computed Tomography } \\
\text { (CT) }\end{array}$ & & \\
\hline Meteorological station & & \\
\hline Geoelectrical surveys & & \\
\hline Ice coring & \multirow{2}{*}{$\begin{array}{l}\text { Analogue } \\
\text { research }\end{array}$} & \multirow{2}{*}{$\begin{array}{l}\text { - Environmental conditions } \\
\text { - Ground-truthing \& cross-measurements }\end{array}$} \\
\hline Field reconnaissance & & \\
\hline
\end{tabular}

\section{Summary}

This paper emphasizes the importance of using terrestrial analogues to improve our understanding of the role of ice on Mars, both in the past and present, through its associated landforms. We present a series of sites of interest for their climate conditions, topography, glaciation history, ice dynamics and mass balance, and presence of specific landforms, that capture past or present conditions on Mars. Because the next natural step in terms of identifying sites with potential for ISRU calls for in-situ investigation of icy regions, we discuss a list of techniques currently used to characterize (peri)glacial environments on Earth. The continued research of Martian (peri)glacial environments through comparative geology is largely relevant for the future of Mars exploration.

References (hyperlinks): ${ }^{1}$ Howard et al., 2005. ${ }^{2}$ Hynek et al., 2010. ${ }^{3}$ Carr and Head, 2015. ${ }^{4}$ Souness et al., 2012. ${ }^{5}$ Levy et al., 2014. ${ }^{6}$ Dickson et al., 2012. ${ }^{7}$ Nunes and Phillips, $2006 .{ }^{8}$ Head et al., 2010. ${ }^{9}$ Banks et al., 2008. ${ }^{10}$ Hobley et al., $2014 .{ }^{11}$ Head and Marchant, 2003. ${ }^{12}$ Head. et al., 2005. ${ }^{13}$ Kargel and Strom, 1992. ${ }^{14}$ Butcher et al., 2017. ${ }^{15}$ Hibbard et al., 2020. ${ }^{16} \mathrm{Cuffey}$ and Paterson, 2010. ${ }^{17}$ Arthern et al., 2000. ${ }^{18}$ Sun and Milliken, 2018. ${ }^{19}$ Rutledge et al., 2018. ${ }^{20}$ Bramson et al., 2020*. ${ }^{21}$ Squyres, $1978 .{ }^{22}$ Plaut et al., 2009. ${ }^{23}$ Holt et al., 2008. ${ }^{24}$ Dundas et al., 2018. ${ }^{25}$ Fastook et al., 2012. ${ }^{26}$ Butcher et al., 2016. ${ }^{27}$ Nye et al., 2000. ${ }^{28}$ Byrne, 2009. ${ }^{29}$ Gallagher and Balme, 2015. ${ }^{30}$ Orosei et al., 2018. ${ }^{31}$ Sharp, 1974. ${ }^{32}$ Rossbacher and Judson, $1981 .{ }^{33}$ Squyres and Carr, 1986. ${ }^{34}$ Boynton et al., 2002. ${ }^{35}$ Mangold et al., 2004. ${ }^{36}$ Smith et al., 2009. ${ }^{37}$ Bramson et al., 2015. ${ }^{38}$ Putzig et al., 2020. ${ }^{39}$ Putzig et al., 2019. ${ }^{40}$ Stuurman et al., 2016. ${ }^{41}$ Ramsdale et al., 2019. ${ }^{42}$ Soare et al., 2014. ${ }^{43}$ Soare et al., 2016. ${ }^{44}$ Lee, $1997 . ~{ }^{45}$ Clarke et al., 2019. ${ }^{46}$ Boon et al., 2010. ${ }^{47}$ Dyke, 1999. ${ }^{48} \mathrm{Grau}$ Galofre et al., 2018. ${ }^{49}$ Hibbard and Osinski, 2019. ${ }^{50} \underline{\text { Rutishauser et al., 2018. }}{ }^{51} \underline{\mathrm{Grau}}$ Galofre et al., 2020. ${ }^{52}$ Fairén et al., 2010. ${ }^{53}$ Shean et al., 2007. ${ }^{54} \mathrm{Head}$ and Marchant, 2014. ${ }^{55}$ Sugden et al., 1991. ${ }^{56} \mathrm{Hauber}$ et al., 2011. ${ }^{57}$ Ulrich et al., 2011. ${ }^{58}$ Elfström and Rossbacher, 1985. ${ }^{59}$ Johnsson et al., 2015. ${ }^{60}$ Gastineau et al., 2019. ${ }^{61}$ Knightly et al., 2020. ${ }^{62}$ Hill et al., 1991. ${ }^{63}$ Soare et al., 2011. ${ }^{64}$ Frolov, 2003. ${ }^{65}$ McKay et al., 1991. ${ }^{66}$ Ulrich et al., 2010. ${ }^{67}$ Komatsu et al., 2007. ${ }^{68}$ Begét et al., 1996. ${ }^{69}$ Marcucci et al., 2017. ${ }^{70}$ Petersen et al., 2020. ${ }^{71}$ Munroe, 2007. ${ }^{72}$ Sinha et al., 2019 ${ }^{73}$ Pandey et al., 2019, ${ }^{74}$ and ${ }^{75}$ Coronato et al., 2004. ${ }^{76}$ Rabassa et al., 2011. ${ }^{77}$ Coronato et al., 2013. ${ }^{78}$ Wilson et al., 2019. ${ }^{79}$ Ponce et al., 2019. ${ }^{80}$ Ercolano et al., 2004. ${ }^{81}$ Ercolano et al., 2016. ${ }^{82}$ Byrne et al., 2019. ${ }^{83}$ Bapst et al., 2020*. ${ }^{84}$ Becerra et al., 2020*. ${ }^{85}$ Smith et al., 2020*, ${ }^{86}$ Obbard et al., 2009. *Indicates White Paper submitted to this Decadal Survey. 